\title{
Correction to: The road from evidence to policies and the erosion of the standards of democratic scrutiny in the COVID-19 pandemic
}

\author{
Giorgio Airoldi ${ }^{1}$ (D) Davide Vecchi $^{2}$ (D)
}

Accepted: 28 May 2021 / Published online: 10 June 2021

(C) Springer Nature Switzerland AG 2021

\section{Correction to: HPLS (2021) 43:66 https://doi.org/10.1007/s40656-021-00419-1}

The name of the second author was misspelt. The correct name reads Davide Vecchi.

The following information has been added to the Acknowledgment section:

Giorgio Airoldi contributed to this article as part of the research project MECABIOSOC "Mechanisms across the Sciences: From Biology to the Social" (FFI2017-89639-P). Davide Vecchi acknowledges the financial support of the FCT - Fundação para a Ciência e a Tecnologia (Grants DL57/2016/CP1479/CT0072, UIDB/00678/2020 and UIDP/00678/2020).

The original article has been corrected.

Publisher's Note Springer Nature remains neutral with regard to jurisdictional claims in published maps and institutional affiliations.

The original article can be found online at https://doi.org/10.1007/s40656-021-00419-1.

Giorgio Airoldi

gairoldi1@icloud.com

Davide Vecchi

davide.s.vecchi@gmail.com

1 Facultad de Filosofía, Departamento de Lógica, Historia y Filosofía de La Ciencia, UNED, Paseo de la Senda del Rey 7, 28040 Madrid, Spain

2 Centro de Filosofia das Ciências, Departamento de História e Filosofia das Ciências, Faculdade de Ciências, Universidade de Lisboa, 1749-016 Lisboa, Portugal 